
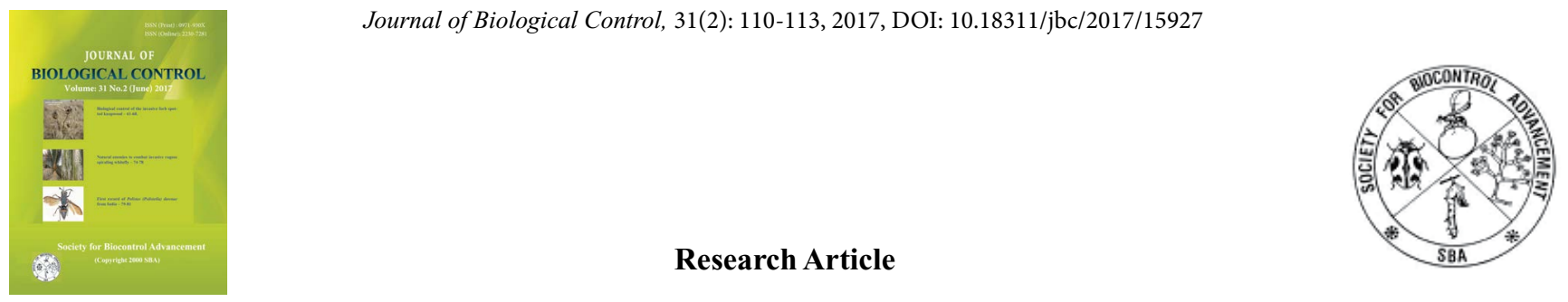

\title{
Biology of Chrysoperla zastrowi sillemi (Esben-Petersen) on mealy bugs and aphids
}

\author{
S. H. MHASKE* , S. S. SHETGAR and P. R. SHINDE \\ Department of Agricultural Entomology, College of Agriculture, Latur - 413 512, Maharashtra, India \\ ${ }^{*}$ Corresponding author E-mail: sagarmhaske2013@gmail.com
}

\begin{abstract}
Studies on biology of Chrysoperla zastrowi sillemi on mealy bugs and aphids indicated that the incubation period of C. zastrowi sillemi was significantly minimum to the extent of 3.94 days on Aphis gossypii followed by 4.19 days (Phenococcus solenopsis) and 4.28 days (Maconellicoccus hirsutus). The significantly maximum egg hatching of C. zastrowi sillemi (89.00 per cent) was observed on $A$. gossypii followed by P. solenopsis ( 86.00 per cent) and M. hirsutus ( 79.00 per cent). The growth index and the larval duration of $C$. zastrowi sillemi were $7.21,5.14 ; 4.83,11.36 ; 12.87,12.61$ days on second instar nymphs of A. gossypii, P. solenopsis and $M$. hirsutus respectively. The significantly lowest pupal duration to the extent of 7.41 days was observed when grown on $P$. solenopsis followed by 7.42 days on $A$. gossypii and 7.95 days on $M$. hirsutus. Significantly the shortest life - cycle duration to the extent of 50.97 and 54.93 days by male and female adult of $C$. zastrowi sillemi was observed on M. hirsutus. The pre-oviposition period (4.50 days) was lowest on A. gossypii while oviposition period (23.40 days) of C. zastrowi sillemi was highest on A. gossypii.
\end{abstract}

KEY WORDS: Aphis gossypii, biology, Chrysoperla zastrowi sillemi, Maconelicoccus hirsutus, Phenococcus solenopsis

(Article chronicle: Received: 26.04.2017; Revised: 10.06.2017; Accepted: 22.06.2017

\section{INTRODUCTION}

Green lacewing, Chrysoperla zastrowi sillemi (Esben - Petersen) (Neuroptera : Chrysopidae) has long been considered as an important natural predator because of its potential to control a variety of soft bodied insects like aphids, coccids, mealybugs, thrips, psyllids, whiteflies, and eggs and larvae of many lepidopteran pests and mites occurring on various crops (Rao and Satyanarayana, 1984). Most of the adult chrysopids are non predatory but their larval instars are predatory. The chrysopids are emerging as potent biocontrol agents against mealybugs and aphids however, further research is needed to ascertain their efficiency in the integrated pest management programme. Hence present investigation on biology of C. zastrowi sillemi on mealy bugs and aphids was carried out.

\section{MATERIALS AND METHODS}

The culture of Chrysoperla zastrowi sillemi available with the National Bureau of Agriculturally Important Resources, Bangalore was used for these studies. The different techniques adopted for the maintenance and mass culture of preys and its predator are given below:

\section{Mass multiplication of Maconelicoccus hirsutus (Green) on pumpkins}

The laboratory technique of rearing of mealy bugs on ripe red pumpkins, Cucurbita maxima standardized by Chacko et al. (1978) and Singh (1978) were adopted for present investigation. The pumpkins were inoculated with egg masses of M. hirsutus (Green) with the help of wet camel hair brush. Number of egg sacs placed on each pumpkin varied according to size of pumpkin. The ambient temperature and relative humidity of the laboratory ranged from $25^{\circ} \mathrm{C}$ to $30^{\circ} \mathrm{C}$ and 65 to 75 per cent, respectively.

\section{Mass multiplication of Phenococcus solenopsis (Tinsley) on potato}

The laboratory technique of rearing of mealy bugs on potato sprouts reported by Branigan (1916) and further modified by Smith and Armitage (1920) and elaborated by Fisher (1963) was used in the present investigation. The Plastic pots having $26 \mathrm{~cm}$ diameter and $24 \mathrm{~cm}$ height were used for plantation of the potatoes. After plantation potatoes were slightly covered with soil. The pots were watered regularly. The potatoes were well sprouted in 10 to 12 days. On such sprouted potatoes the ovisacs of P. solenopsis (Tin- 
sley) were transferred. The mass culture of mealy bugs was maintained throughout the period of investigation.

\section{Mass multiplication of Aphis gossypii (Glover) on cotton}

The culture of aphids was obtained from the pesticide free cotton variety $\mathrm{RCH}-2 \mathrm{BG}-\mathrm{II}$ grown in a plot size of $5 \mathrm{x}$ 5 sq.m at the spacing of $45 \times 10 \mathrm{~cm}$.

\section{Multiplication of Crysoperla zastrowi sillemi (Esben- Petersen):}

The culture of $C$. zastrowi sillemi eggs was obtained from ICAR-NBAIR, Bangalore. After adult emergence the adults were differentiated as male and female sex by observing thickness of abdomen. The females were with swollen while males with narrow and thin abdomen. The adults that emerged on the same day were placed in oviposition cage for the purpose of egg laying. The castor pollens and cotton swabs dipped into drinking water, 50 per cent honey solution and proteinex mixture (equal quantity of proteinex + fructose + honey + powdered yeast dissolved in small quantity of water) were kept in the lid of plastic container $(15 \times 12 \mathrm{~cm})$ as food for the adults. The inner surface and top of the container were covered by black century thick paper in order to serve as oviposition substrate. Thus, the freshly laid eggs were used for investigation on biology of C. zastrowi sillemi on mealy bugs and aphids.

\section{Biological studies}

The studies on biology of C. zastrowi sillemi, M. hirsutus and P. solenopsis and A. gossypii was carried out in a completely randomized design replicated five times at the temperature of $25 \pm 2^{\circ} \mathrm{C}$ maintained in BOD incubator. One hundred freshly laid eggs of C. zastrowi sillemi were kept in five petri dishes each containing 20 eggs as a replicate.
The observations were recorded in respect of incubation period and per cent egg hatch. The newly hatched larvae were reared individually on mealy bugs and aphids in the vials (4 $\mathrm{x} 2 \mathrm{~cm}$ ) food were changed daily. The observations on the larval duration, per cent larvae pupated, growth index, pupal duration, adult emergence and life-cycle duration were recorded castor pollens, moinstened cotton swabs dipped into drinking water, 50 per cent honey solution and proteinex mixture were provided daily to the adults. The black century thick paper was used to cover the inner surface and top of the oviposition cage to serve as oviposition substrate. 10 pairs of adults were kept for observing fecundity. The number of eggs laid by each female was counted daily till its death.

The growth index was calculated by using Howe (1953) formula.

Growth index $=\frac{\text { Per cent larvae pupated }}{\text { Mean larval duration (days) }}$

\section{RESULTS AND DISCUSSION}

Minimum incubation period of Crysoperla zastrowi sillemi reared on $A$. gossypii was 3.94 days which was significantly different from that reared on P. soleopsis (4.19 days) and $M$. hirsutus (4.28 days) The incubation period of $C$. zastrowi sillemi was found to be $3.09 \pm 0.23$ days when fed on A. gossypii infesting cotton (Kapadia and Puri, 1992). Saminathan et al. (1999) recorded the incubation period of $C$. zastrowi sillemi to the tune of 3.45 days when reared on $A$. gossypii. The significantly highest egg hatching of C. zastrowi sillemi was recorded when fed on A. gossypii ( 89.00 per cent) followed by $P$. solenopsis ( 86.00 per cent) and $M$. hirsutus (79.00 per cent).

Table 1. Biology of Crysoperla zastrowi sillemi on mealy bugs and aphids

\begin{tabular}{|c|c|c|c|c|c|c|}
\hline Biological parameters & Preys used for & ysoperla zastro1 & llemi & $\mathrm{SEm} \pm$ & $\mathrm{CD}$ at $5 \%$ & $\mathrm{CV}(\%)$ \\
\hline & Aphis gossypii & $\begin{array}{l}\text { Phenococcus } \\
\text { solenopsis }\end{array}$ & $\begin{array}{l}\text { Maconellicoc- } \\
\text { cus hirsutus }\end{array}$ & & & \\
\hline Mean incubation period & 3.94 & 4.19 & 4.28 & 0.04 & 0.13 & 2.22 \\
\hline Per cent egg hatch & $\begin{array}{c}89.00 \\
(70.92) \\
\end{array}$ & $\begin{array}{r}86.00 \\
(68.54) \\
\end{array}$ & $\begin{array}{c}79.00 \\
(62.86) \\
\end{array}$ & 2.45 & 7.54 & 6.47 \\
\hline Mean larval duration (days) & 11.36 & 12.87 & 12.61 & 0.13 & 0.39 & 2.33 \\
\hline Mean per cent larvae pupated & $\begin{array}{r}81.94 \\
(64.90) \\
\end{array}$ & \begin{tabular}{|c|}
66.15 \\
$(54.47)$ \\
\end{tabular} & $\begin{array}{c}60.82 \\
(51.25) \\
\end{array}$ & 1.76 & 5.41 & 5.64 \\
\hline Growth index & 7.21 & 5.14 & 4.83 & 0.16 & 0.50 & 6.37 \\
\hline Mean pupal duration (days) & 7.42 & 7.41 & 7.95 & 0.13 & 0.40 & 3.88 \\
\hline Per cent adult emergence & $\begin{array}{r}80.16 \\
(63.63) \\
\end{array}$ & $\begin{array}{r}88.03 \\
(70.03) \\
\end{array}$ & $\begin{array}{r}86.32 \\
(68.54) \\
\end{array}$ & 2.00 & 6.16 & 5.27 \\
\hline Total developmental period & 22.72 & 24.48 & 24.67 & 0.20 & 0.62 & 1.87 \\
\hline Pre-oviposition period (days) & 4.50 & 4.70 & 5.30 & 0.13 & 0.42 & 6.26 \\
\hline Oviposition period (days) & 23.40 & 20.80 & 19.20 & 0.30 & 0.91 & 3.14 \\
\hline Fecundity / female & \begin{tabular}{|l}
393.9 \\
$(19.92)$ \\
\end{tabular} & \begin{tabular}{|l}
227.1 \\
$(15.07)$ \\
\end{tabular} & $\begin{array}{l}127.9 \\
(11.30) \\
\end{array}$ & 3.73 & 11.50 & 3.33 \\
\hline
\end{tabular}


Fathipour and Jafari (2004) reported 88.42 per cent egg hatch of C. zastrowi sillemi on mirid bug. Adsul (2009) observed egg hatching of C. zastrowi sillemi to the tune of 94 per cent on $U$. carthami followed by L. erysimi ( 93 per cent), B. brassicae ( 89 per cent) and A. craccivora ( 78 per cent). Takalloozadeh (2015) observed egg hatching of $C$. zastrowi sillemi to the tune of 89.15, 91.22, 90.65, 95.12 and 88.95 per cent on A. panicae, M. persicae, A. craccivo$r a, A$. gossypii and $A$. fabae, respectively. The shortest mean larval duration of $C$. zastrowi sillemi to the extent of 11.36 days was observed when fed on A. gossypii followed by $M$. hirsutus (12.61 days) and P. solenopsis (12.87 days).This indicates that the grub period of C. zastrowi sillemi was lengthened when grown on $P$. solenopsis.

The significantly highest pupation of $C$. zastrowi sillemi was recorded when fed on second instar nymphs of $A$. gossypii (81.94 per cent) followed by P. solenopsis (66.15 per cent) and $M$. hirsutus (60.82 per cent). The growth index values varied from 4.83 to 7.21 . The significantly highest growth index was observed in the case of larvae which fed on second instar nymphs of $A$. gossypii (7.21) over P. solenopsis (5.14) and M. hirsutus (4.83). According to Bansod and Sarode (2000), Dhepe (2001), Khuhro et al. (2012) and Takalloozadeh (2015) the duration of larvae of C. zastrowi sillemi were 9.82, 9.87, 9.60 and 9.92 days when reared on A. gossypii respectively.

The significantly minimum pupal duration of C. zastrowi sillemi was found to be 7.41 days when reared on $P$. solenopsis followed by A. gossypii (7.42 days) and M. hirsutus (7.95 days). Mannan et al. (1997), Thite and Shivpuje (1999), Geetalakshmi et al. (2000) and Chakraborty and Korat (2010) recorded the pupal period of $C$. zastrowi sillemi to the extent of $9.43,8.40,8.40$ and $6.92 \pm 0.13$ days when its larval stage fed on $A$. gossypii, respectively. The significantly highest adult emergence was observed in the case of larvae which were reared on P. solenopsis ( 88.03 per cent) followed by $M$. hirsutus ( 86.32 per cent) and A. gossypii ( 80.16 per cent). The mean total developmental period of C. zastrowi sillemi was observed to be significantly lowest when reared on A. gossypii (22.72 days) over rest of the preys under investigation. This indicates that the total developmental period of C. zastrowi sillemi was lengthened when grown on M. hirsutus as compared to A. gossypii and P. solenopsis.

The data revealed that pre-oviposition period (5.30 days) of C. zastrowi sillemi was significantly lengthened as compared to the larvae fed on P. solenopsis (4.70 days) and $A$. gossypii (4.50 days). However, its oviposition period was found to be significantly highest on A. gossypii (23.40 days) followed by P. solenopsis (20.80 days) and M. hirsutus (19.20 days). Significantly highest eggs (396.9) were laid by female $C$. zastrowi sillemi when its larvae fed on A. gossypii followed by P. solenopsis (227.1) and M. hirsutus (127.9). Mannan et al. (1997) observed that the preoviposition, oviposition and post-oviposition periods of $C$. zastrowi sillemi on A. gossypii and M. persicae were 6.55, 21.10 and 7.95 days and 9.25, 21.85 and 11.20 days, respectively. Sattar et al. (2011) observed that the pre-oviposition, oviposition and post-oviposition periods of $C$. zastrowi sillemi on A. gossypii and P. solenopsis were $3.37 \pm 0.18$ and $3.62 \pm 0.18,27.62 \pm 0.42$ and $21.62 \pm 0.49$ and 6.87 \pm 0.47 and $7.00 \pm 0.56$ days, respectively. Significantly highest eggs (396.9) were laid by female $C$. zastrowi sillemi when its larvae fed on A. gossypii followed by P. solenopsis (227.1) and M. hirsutus (127.9).

Table 2. The mean longevity and life-cycle duration of Crysoperla zastrowi sillemi on mealy bugs and aphids

\begin{tabular}{|l|l|l|l|l|}
\hline \multirow{2}{*}{ Name of prey } & \multicolumn{2}{|c|}{$\begin{array}{c}\text { Longevity } \\
\text { (days) }\end{array}$} & \multicolumn{2}{c|}{$\begin{array}{c}\text { Life-cycle duration } \\
\text { (days) }\end{array}$} \\
\cline { 2 - 5 } & Male & Female & Male & Female \\
\hline Aphis gossypii & 30.7 & 34.9 & 53.42 & 57.62 \\
\hline Phenococcus solenopsis & 25.5 & 31.0 & 49.98 & 55.48 \\
\hline Maconellicoccus hirsutus & 26.3 & 30.2 & 50.97 & 54.93 \\
\hline S.E \pm & 0.06 & 0.06 & 0.02 & 0.25 \\
\hline C.D at 5\% & 0.17 & 0.19 & 0.05 & 0.79 \\
\hline C.V. (\%) & 0.47 & 0.41 & 0.08 & 1.02 \\
\hline
\end{tabular}

Significant differences were observed in respect of longevity of male and female C. zastrowi sillemi when reared on mealy bugs and aphids. The significantly highest longevity of male and female $C$. zastrowi sillemi was recorded on A. gossypii (30.7 and 34.9 days). It was followed by the longevity of male and female C. zastrowi sillemi on P. solenopsis (25.5 and 31.0 days) and M. hirsutus (26.3 and 30.2 days). Kapadia and Puri (1992) reported that the female and male C. zastrowi sillemi survived for 39 to 56 and 28 to 48 days, respectively on A. gossypii.

The significantly shortest life-cycle duration of male and female C. zastrowi sillemi to the extent of 49.98 and 55.48 days was observed on $P$. solenopsis followed by lifecycle duration of the male and female $C$. zastrowi sillemi on M. hirsutus (50.97 and 54.93 days) while, it was longest (53.42 and 57.62 days) when grown on $A$. gossypii.

It indicates from the present investigation on biology of C. zastrowi sillemi grown on species of mealy bugs and aphids that the durations of different life-stages excepting longevity of male and female were shortened when grown on aphids. The its egg hatch, pupation, oviposition period, fecundity and longevity of male and female was increased. 
This could be because of variations in the nutritional status of different host insects used in the investigation, when grown on $A$. gossypii as compared to their durations when grown on $P$. solenopsis and M. hirsutus.

\section{ACKNOWLEDGEMENTS}

The authors are thankful to Director, ICAR-NBAIR, India for providing the culture of Chrysoperla zastrowi sillemi and also thanks to Dr. Shetgar S. S., Principal, College of Agriculture, Latur for providing the necessary facilities for undertaking the present study.

\section{REFERENCES}

Adsul HG. 2009. Biology, life-fecundity and predatory potential of Chrysoperla zastrowi sillemi (EsbenPetersen) on aphids. M.Sc. (Agri.) dissertation submitted to Marathwada Agricultural University, Parbhani (Unpublished).

Bansod RS, Sarode SV. 2000. Influence of different prey species on biology of Chrysoperla zastrowi sillemi (Esben-Petersen). Shashpa 7(1): 21-24.

Branigan EJ. 1916. A satisfactory method of rearing mealy bugs for use in parasite work. Monthly Bull Calif State Comm Hort. 5: 304-306

Sreedharan K. 1978. The use of lady bird-beetle Cryptolaemus montrouzieri for the control of Coffee mealy bugs. J Coff Res. 8: 14-19.

Chakraborty D, Korat DM. 2010. Feeding efficiency of green lacewing, Chrysoperla zastrowi sillemi (EsbenPetersen) on different species of aphids. Karnataka $J$ Agri Sci. 23(5): 793-794.

Dhepe VR. 2001. Studies on biology of Chrysoperla zastrowi sillemi (Esben-Petersen) on different hosts. M.Sc. (Agri.) dissertation submitted to Dr. Punjabrao Deshmukh Krishi Vidhyapeeth, Akola, Maharashtra, India (Unpublished).

Fatipour Y, Jafari A. 2004. Biology of Chrysoperla zastrowi sillemi on Creontiades pallidus (Heteroptera: Miridae) (Mirid bug). Iranian J Agric Sciences 35(3): 721-729.

Fisher TW. 1963. Mass culture of Cryptolaemous and Leptomastix, natural enemies of citrus mealy bug. Bull Calif Agric Exp St. 797: 39.

Geetalakshmi L, Muthukrishnan N, Chandrashekaran M, Raghuraman M. 2000. Chrysopids biology on Corcyra cephalonica and feeding potential on different host insects. Ann Pl Prot Sci. 8(2): 132-135.
Howe RW. 1953. The rapid determination of intrinsic rate of increase of an insect population. Ann Appl Biol. 40: 134-155. Crossref

Kapadia MN, Puri SN. 1992. Development of Chrysoperla zastrowi sillemi reared on aphids and whitefly. $J$ Maharashtra Agric Univ. 17(1): 163-164.

Khuhro NH, Chen H, Zhang Y, Zhang L, Wang M. 2012. Effect of different prey species on the life history parameters of Chrysoperla sinica (Neuroptera: Chrysopidae). Eur J Entomol. 109: 175-180. Crossref

Mannan VD, Varma GC, Bras KS. 1997. Biology of Chrysoperla zastrowi sillemi (Esben-Petersen) on Aphis gossypii (Glover) and Myzus persicae (Sulzer). J Insect Sci. 10(2): 143-145.

Rao RSN, Sathyanarayana SVV. 1984. Note on more additions to the natural enemy complex of Spodoptera litura F. and Myzus persicae Sulz. on tobacco in Andhra Pradesh. Curr Sci. 53(4): 201-202.

Saminathan VR, Muralibaskaran RK, Mahadevan NR. 1999. Biology and predatory potential of green lacewing, Chrysoperla zastrowi sillemi (Neuroptera : Chrysopidae) on different insect hosts. Indian J Agric Sci. 69(1): 502-505.

Sattar M, Abro GH, Syed TS. 2011. Effect of different hosts on biology of Chrysoperla zastrowi sillemi (EsbenPetersen) (Neuroptera: Chrysopidae) in laboratory conditions. Indian J Agric Sci. 69(1): 1049-1054.

Smith HS, Armitage HM. 1920. Biological control of mealy bugs in California. Calif State Dept Agri Monthly Bull. 9: $104-158$.

Singh SP. 1978. Propagation of coccinellid beetle for biological control of citrus and coffee mealy bugs. Scientific Conference, CPA, Dec., 1978: 2.

Takalloozadeh HM. 2015. Effect of different prey species on the biological parameters of Chrysoperla zastrowi sillemi (Esben-Petersen). (Neuroptera: Chrysopidae) in laboratory conditions. J Crop Prot. 4 (1): 11-18.

Thite NR, Shivpuje PR. 1999. Biology, feeding potential and development of Chrysoperla zastrowi sillemi (EsbenPetersen) on Aphis gossypii (Glover). J Maharashtra Agric Univ. 24 (3): 240-241. 